\title{
Conseguir el mejor aprendizaje en Derecho de Familia, como objetivo docente
}

\section{Get the best learning in Family Law, as a teaching goal}

Patricia Craviotto Valle

ORCID: https://orcid.org/0000-0002-8754-4769

Universidad de Sevilla

Departamento de Derecho Civil

e Internacional Privado

pcraviotto@us.es

DOI: http://dx.doi.org/10.12795/9788447231003.014

Pp.: 292-312 


\section{Contextualización de la intervención}

El presente capítulo expone el trabajo realizado en las aulas de la Facultad de Derecho de la Universidad de Sevilla, respecto a la mejora del aprendizaje de los alumnos de 4으 curso del Grado en Derecho, en la asignatura Derecho Civil IV: Derecho de Familia y Sucesiones.

El Programa de Formación e Innovación Docente del Profesorado de la Universidad de Sevilla -FIDOP-, promueve en sus docentes inquietudes en el ámbito del aprendizaje universitario. El buen profesor, tiene dos ámbitos de actuación en su trabajo: la tarea de cultivarse y la labor de hacer que otros aprendan. Dicho de otra manera: (i) debe tener un gran conocimiento sobre su materia e ir reciclándola y actualizándola, y (ii) debe tener la capacidad y destreza de saber compartir su conocimiento, con el objetivo de que otros adquieran el mismo. Ser experto en una determinada materia, no implica necesariamente ser un buen docente. Si el objetivo más común en los estudiantes suele ser superar la asignatura con un aprobado, la pretensión del buen profesor debería ser la de que éste -el alumno-, consiga llegar al mejor nivel de aprendizaje posible. En esta vía, el concepto de "estudiar una carrera", cambiará sustancialmente en el alumno. Lo importante no es aprobar, sino aprender.

El aprendizaje del alumno en el Grado en Derecho suele desarrollarse de manera muy individual: trabajo y esfuerzo personal, pocas veces compartido con los compañeros de clase. El objetivo de mejora de su aprendizaje es el de acercarnos un poco más al mismo, gracias al uso de herramientas que nos permitan adquirir un conocimiento adecuado -o más adecuado-. El estudiante de Derecho de Familia y Sucesiones, al final del curso debería lograr un nivel de conocimiento excelente, puesto que, de su aprendizaje depende la aplicación inmediata del Derecho en su sociedad. Alcanzar Justicia, o no, en gran medida

Ciclos de Mejora en el Aula (2020). Experiencias de Innovación Docente de la US Esta obra se distribuye con la licencia Creative Commons 
dependerá del aprendizaje previo que el alumno desarrolle a lo largo de su paso por la Universidad. No es una cuestión de memorización de artículos y casos prácticos. Es una cuestión de conocimiento de alto nivel y correcta aplicación -social- del mismo.

\section{Diseño del Ciclo de Mejora}

Considerar mi perfil académico multidisciplinar -Jurista e Ingeniera de la Edificación-, como un hándicap en la docencia, sería de necios. Todo lo contrario: es una gran oportunidad la que ofrezco a mis alumnos, dados los distintos ángulos desde los que me planteo la asimilación del conocimiento. Un enriquecimiento añadido. Por ello, y en base a mi experiencia, mi docencia nunca se basó en la memorización. Sin embargo, he experimentado un trabajo de derribo y reconstrucción sobre lo que, hasta el momento, yo entendía que debían aprender mis alumnos. Derribo, respecto a algunos contenidos en mi docencia, y reconstrucción, respecto a qué y en qué orden han de relacionarse para su posterior asimilación. Necesitaba progresar y perfeccionarme como profesional, por lo que el CIMA ha sido definitivamente una necesidad. Para comprender el diseño de mi ciclo de mejora, es necesario poner en antecedentes, ciertas circunstancias.

El Derecho de Familia y Sucesiones en particular, no es una materia de fácil comprensión, ni sucinta en cuanto a contenidos. La lógica y la interpretación en los estudios de Derecho, no se aplican de la misma manera que en otros campos del conocimiento, por lo que hay un trabajo añadido de esfuerzo -no memorístico-, necesario para relacionar las normas actuales con la aplicación de éstas en nuestra sociedad. El positivismo de las normas jurídicas aplicables -Código Civil y Ley de Enjuiciamiento Civil-, no promueve la participación crítica del alumno. Éstos parten -en 40 curso-, de una base generalizada en la que el Derecho ha de aplicarse de memoria, conteniendo una carga

Ciclos de Mejora en el Aula (2020). Experiencias de Innovación Docente de la US Esta obra se distribuye con la licencia Creative Commons 
histórica muy potente difícilmente rebatible, por lo que el alumno tiende únicamente a memorizar conceptos y normas. Modelos previos que ni siquiera se plantean aceptándolos como tal. Un escollo que considero hay que tener muy en cuenta en Derecho de Familia, especialmente porque no existen dos familias iguales.

No se trata únicamente de que el profesor transmita con sus explicaciones los contenidos y/o experiencias necesarias para superar un nivel que se materialice en un aprobado. Se trata de que el alumno haga suyo el conocimiento que aún no posee, escuchando, participando, proponiendo, realizando críticas constructivas, trabajando en equipo e individualmente, etc. El alumno de Derecho Civil IV, necesita un/a profesor/a, que sepa qué deben aprender y cómo deben hacerlo. Esta labor no es de ellos, sino nuestra: de los profesores universitarios.

El docente en Derecho de Familia y Sucesiones no debe aferrarse a la costumbre de impartir clases magistrales que no mejoran ni exprimen el potencial de sus alumnos. Los cuestionarios, los mapas conceptuales, las secuencias de actividades, etc., son excelentes herramientas que pueden ayudar al profesor universitario, si este sabe cómo manejarlas.

Se da la circunstancia de que, en el momento de la implementación de mi CIMA, la actividad docente universitaria tuvo que ser modificada por la segunda ola COVID, por lo que se desarrolló semipresencialmente. La totalidad del grupo ha estado compuesta por ciento cincuenta alumnos matriculados, pero la presencialidad en las aulas ha sido solo de un tercio. Es decir, la primera semana de curso acudió presencialmente a las aulas el subgrupo de alumnos 1 -cincuenta alumnos-, y el resto se conectó virtualmente por la plataforma de la Universidad de Sevilla, para el seguimiento de las clases. A la semana siguiente debía acudir presencialmente el subgrupo 2 y el resto online, y así sucesiva y rotativamente. Por ello, de manera presencial he intervenido con un tercio de alumnos en el

Ciclos de Mejora en el Aula (2020). Experiencias de Innovación Docente de la US Esta obra se distribuye con la licencia Creative Commons 
aula, y de manera online con dos tercios de este grupo de alumnos. Esto sí es un hándicap. La temporalización se ha llevado a cabo durante dos semanas de clase: la última del mes de octubre y la primera del mes de noviembre de 2020. Cada sesión/clase dura una hora, y cada semana tiene tres sesiones, por lo que se ha implementado en un total de seis horas.

El mapa de contenidos que he aplicado en mi CIMA me costó materializarlo, pues la tendencia que un/a profesor/a tiene cuando ha sido alumno/a en esa materia, es la de enseñar lo aprendido, sin renovaciones o alteraciones sustanciales. El Derecho de Familia español, tiene una antigüedad cuyas bases parten de la época romana. Desbancar contenidos, por pocos que estos sean, no es una labor fácil. Máxime cuando es lo común en esta rama del conocimiento.

El modelo metodológico es otra de las herramientas obtenidas en el curso, de manera que he necesitado replantearme mi relación docente respecto al alumnado: dar más espacio a sus participaciones -mermando las mías-, promover la curiosidad y la crítica con casos reales y actuales, plantear conflictos para que intenten resolverlos conforme avanzan en su aprendizaje, etc. Dado que las sesiones de mis clases son de una hora, debía cuestionarme cuáles son las etapas por las que debíamos ir avanzando. Cómo y en qué orden participar, si es que era necesario un orden preestablecido para ello.

Los cuestionarios han aportado mucha información respecto a tres circunstancias: (i) lo que los alumnos sabían antes de entrar en profundidad en materia, (ii) lo que aprendieron tras las sesiones en el aula, y (iii) si mi docencia iba -o no- por buen camino, pudiendo así reflexionar y tomar decisiones al respecto.

La secuencia de actividades ha proporcionado orden en mi modelo metodológico. Orden que debe ser acompasado entre la secuencia de actividades y el modelo metodológico, puesto que no solo han de ser compatibles, sino que uno respecto al otro deben ser reconocibles.

Ciclos de Mejora en el Aula (2020). Experiencias de Innovación Docente de la US Esta obra se distribuye con la licencia Creative Commons 
En todo caso, la aplicación de mi CIMA en las aulas, podría descomponerse -a efectos de análisis de mejora-, en función de las herramientas comentadas, entrando con mayor profundidad en las mismas.

\section{Mapa de contenidos y problemas}

En la asignatura que imparto no es posible mejorar la docencia, si previamente el profesor no se plantea un mapa de contenidos real y adecuado a las circunstancias de su materia, sus alumnos, y la realidad que viven en ese momento. El Derecho de Familia, quizá sea dentro del Derecho Civil, la materia que más va cambiando con el paso del tiempo, motivo por el que un mapa de contenidos actualizado se convierte en una necesidad -más que una herramienta-, con la que no quedarnos desfasados.

Mi mapa de contenidos versa en torno a la familia, sin abarcar la totalidad de la materia. Me centro en una parte del curso, dándole peso a lo que hoy es la familia, y cómo ésta se regula o no. Los estudios en Derecho Civil, y en concreto los de Derecho de familia, se ven mermados por la falta de inclusión de situaciones reales, donde el reconocimiento jurídico de determinados tipos de familia es inexistente. Es el caso de las parejas de hecho -que no de derecho, inscritas en sus pertinentes Registros de Parejas de Hecho-. Las familias son reconocidas por nuestra sociedad, pero no por las normas. Hoy no puede entenderse la docencia en Derecho de Familia, si se obvia jurídicamente a un gran número de relaciones de pareja -que forman verdaderas familias-. El acceso a los tribunales es la única protección que les queda para -por ejemplo-, pedir el reconocimiento de pensiones compensatorias, viudedad, sucesiones, etc. Al no estar reguladas, estas familias no se estudian y caen así en un mayor desamparo si cabe.

A pesar de que los manuales actuales no recogen este tipo de relaciones familiares, mi mapa de contenidos sí las recoge. Las grandes cuestiones deben girar acerca de si

Ciclos de Mejora en el Aula (2020). Experiencias de Innovación Docente de la US Esta obra se distribuye con la licencia Creative Commons 
debemos regular estos $u$ otros tipos de relaciones de familia, las cuales hoy día no se contemplan ni en el Código Civil, ni en las normas jurídicas estatales o autonómicas. El mapa pretende centrar la atención en que el concepto de familia que tenemos hoy regulado, no casa bien con las familias reales. Los alumnos deben observar este mapa, y comprobar la dicotomía entre las familias reconocidas y las no reconocidas jurídicamente hoy, y los efectos que de estas pueden dirimirse. ¿Hemos de hacer caso omiso a la realidad existente? ¿Han de ser nuestros -hoy- alumnos, solo conocedores de una parte de la realidad, porque en nuestros contenidos académicos, no se cuenta con lo que no se introduce en los planes de estudio? El estudiante ha de conocer y aprender todo tipo de relación familiar regulada, pero no puede hacer caso omiso a lo expuesto.

Mi mapa rompe algún que otro esquema, sin dejar en ningún momento a un lado, materias y contenidos necesarios y tan reales como los no reconocidos. Quizá sea un esfuerzo plus para el alumno. Mi pretensión no es aumentarles el volumen de trabajo, sino complementarlo, descartando profundizar en asuntos demasiado particulares y repetitivos, pudiendo más adelante especializarse en ellos.

La única manera de que, en Derecho de Familia, el alumno haga suyo el mismo, es actualizando continuamente una materia tan dinámica como lo son las relaciones de parejas y las familiares, y no anquilosándonos en la repetición de contenidos, algunos de los cuales son obsoletos o cuasi obsoletos.

Por otro lado, y de manera indisoluble al modelo metodológico diseñado, he de tener en cuenta los problemas que se circunscriben a los contenidos expuestos. Es decir, si existen cuestiones sin resolver, que no se ajustan bien o que son obviadas, nos encontramos ante un conflicto sumergido en los contenidos. Concretamente en mi mapa de contenidos, advierto -de manera llamativa-, las incongruencias existentes hoy día, en relación a la no regulación jurídica respecto a algunos modelos de familia. El Código

Ciclos de Mejora en el Aula (2020). Experiencias de Innovación Docente de la US Esta obra se distribuye con la licencia Creative Commons 
Civil y las normas afectas a las Familias, dedican un contenido muy extenso a la institución del matrimonio y a las consecuencias devenidas por las crisis matrimoniales. Sin embargo, nada se estudia en Derecho de Familia en relación a las Parejas de Hecho -inscritas o no en sus respectivos registros-. En la práctica diaria, y en vista de que la realidad social revela que cada vez hay menos parejas que contraen matrimonio y más que conviven igualmente, pero sin estar casados, hallamos un enorme problema jurídico -cualitativo y cuantitativo-, por la falta de regulación de estas relaciones, que van incrementándose con el tiempo. Ante la falta de normas que regulen estas relaciones, y dado que la mayoría de crisis de pareja procuran resolverse por la vía jurídica, encontramos que los jueces no pueden aplicar normas que no existen. Por ello, le planteo a los alumnos si ellos regularían -o no- esta realidad, al cerrar este ciclo de estudio.

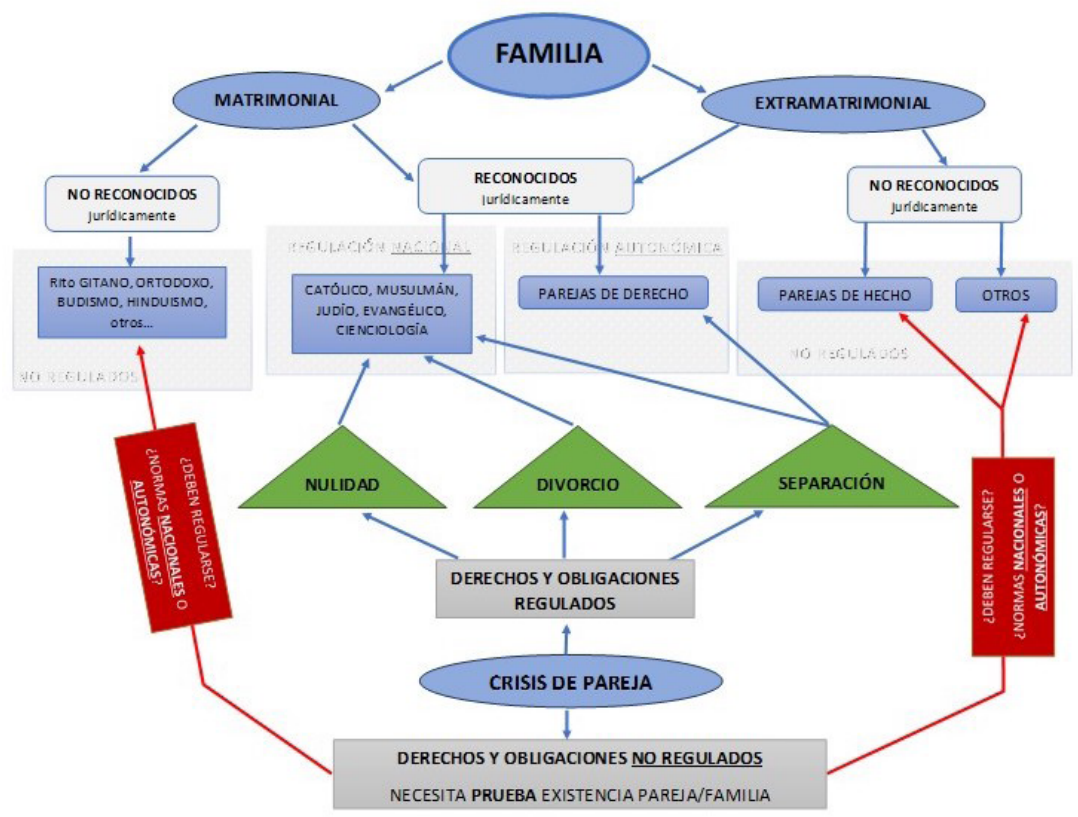

Figura 1. Mapa de contenidos

Ciclos de Mejora en el Aula (2020). Experiencias de Innovación Docente de la US Esta obra se distribuye con la licencia Creative Commons 
Tras la experiencia del confinamiento en marzo de 2020, realizar un modelo metodológico en modo semipresencial no deja de ser un reto. Por ello, para poder diseñar un CIMA adecuado a las circunstancias, lo cierto es que me ha costado un esfuerzo añadido a si el diseño lo hubiera realizado en un momento en el que toda la docencia fuese presencial. A pesar de que la memoria no es algo que valore extraordinariamente como profesora -por lo que recomiendo al alumnado que comprenda lo que lee, lo que escucha y lo que vive, antes de memorizar-, la observación me conduce a la reflexión, y añade un valor a mi trabajo que tenía arrinconado: he de escuchar más al alumnado. Ellos son los únicos que pueden mostrarme el pulso con el que respiran: cómo van aprendiendo. Para ello he aprendido que, para escuchar, debo callar, promoviendo sus participaciones. Pero al escucharlos, y dado que el tiempo que tenemos es limitado, debo tener en cuenta que he de ser una excelente gestora del mismo: el tiempo para 151 personas, yo incluida.

Lo que más llama la atención, en el esquema de mi modelo metodológico, es el volumen que representa el tiempo de la sesión donde la participación de los alumnos se funde con el de su profesora: el aumento de participación del alumnado durante las clases se visualiza y distingue claramente, respecto a otras participaciones más individualizadas. El color pretende distinguir visualmente a quienes participamos en el modelo. No es casual que, al introducir actividades realizadas por la profesora, en amarillo, junto con actividades del alumnado, en azul, nos hallemos ante el verde: un compendio o mezcla de colores, que asimila la fusión en el método creado.

Mi modelo metodológico tiene, como principal objetivo, que las sesiones sean más participativas por parte

Ciclos de Mejora en el Aula (2020). Experiencias de Innovación Docente de la US Esta obra se distribuye con la licencia Creative Commons 
del alumnado. Que se pregunten entre ellos dudas, y que planteen problemas actuales, los cuales nos interesan a todos, ya que todos - de una forma u otra-, formamos parte de una familia concreta. Por ello parto de una pregunta inicial: les propongo una cuestión a pensar y resolver durante la clase, íntimamente relacionada con lo que se va a trabajar ese día. A pesar de que promuevo en este modelo la participación del estudiante, opino que las sesiones de Derecho de Familia no pueden ser, de ninguna manera, dirigidas por el alumno, pues la dirección y el control de lo que ocurre en las aulas de Derecho de Familia y Sucesiones, es responsabilidad del profesor: una materia muy amplia, compleja y transversal.

No considero positivo una anárquica y desordenada actuación, donde simplemente se resuelvan dudas, previa la lectura de manuales, artículos, etc., por parte de los alumnos. Dado el gran volumen de contenidos en sus estudios del Grado, la mayoría de ellos no realizaría ese estudio previo -sin guía alguna-, sumado a la tendencia que el alumno de Derecho tiene a particularizar en casos personales. Así se alejarían de lo fundamental e importante, imposibilitando por ello un correcto aprendizaje.

No obstante, este modelo metodológico puede ser mejorado. Cada curso académico es distinto, incluso cada cuatrimestre. En Derecho, continuamente nos asaltan nuevas normas que pretenden -con más o menos acierto-, mejorar nuestra sociedad. La crítica ha de formar parte del aprendizaje universitario. Procuro promover la participación del alumnado, y para ello son necesarias las explicaciones previas y también el planteamiento de mini casos reales, a los que los alumnos dan soluciones. Pero, sin duda, lo más enriquecedor son las actividades de contraste, las cuales ocupan gran parte del tiempo, como puede comprobarse en el gran círculo.

Ciclos de Mejora en el Aula (2020). Experiencias de Innovación Docente de la US Esta obra se distribuye con la licencia Creative Commons 


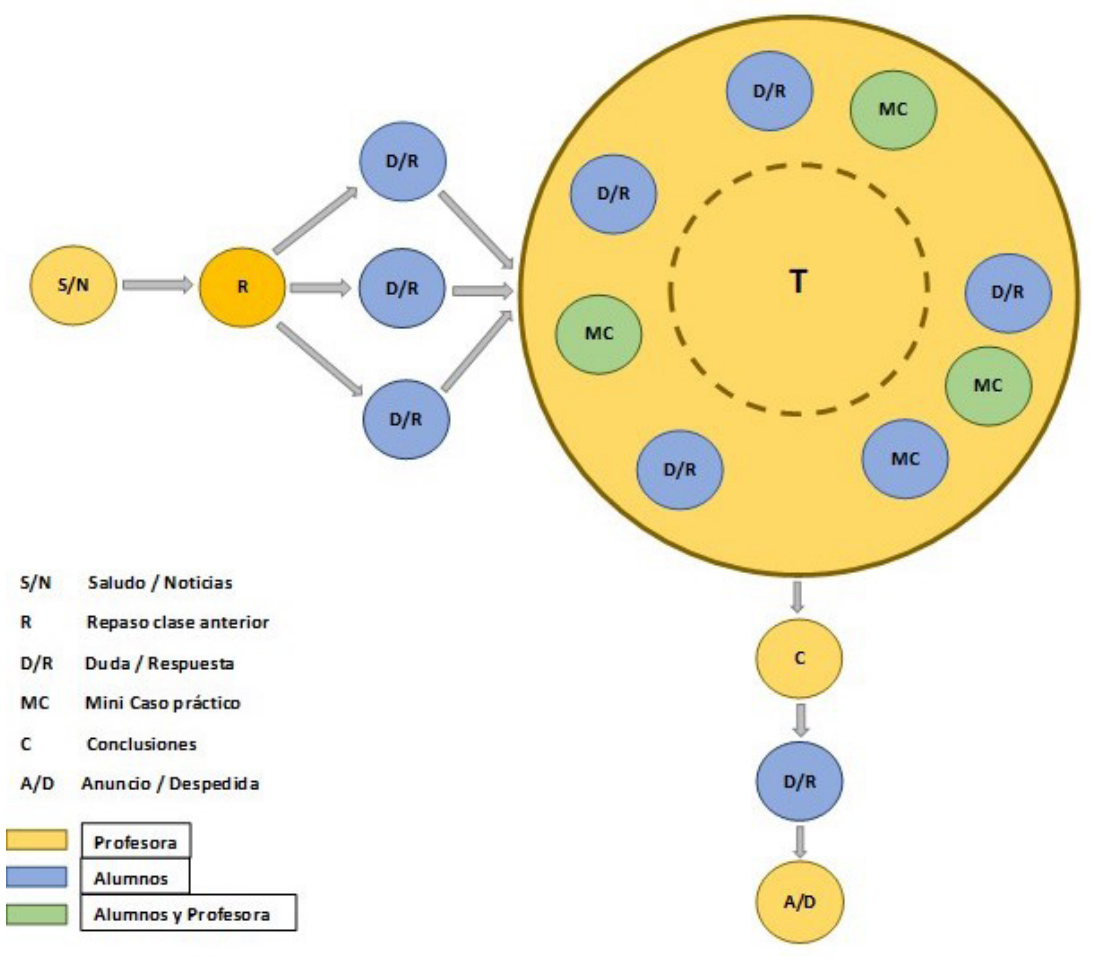

Figura 2. Modelo Metodológico

Cuestionarios inicial y final: una información valiosa para tomar decisiones

Los cuestionarios iniciales y finales me han dado cantidad de información sobre el aprendizaje del alumno desconocida hasta el momento. Ab initio consideraba muy apropiadas mis preguntas, y hoy me doy cuenta de lo mejorables e imperfectas que son.

En el primer cuestionario respondieron 131 y en el segundo cuestionario respondieron 128. Necesitaba respuestas francas para ver en qué nivel de aprendizaje se encontraban. Las respuestas del primer cuestionario fueron más personales que jurídicas, y esa falta de definición -por mi parte-, fue un error que no cometí al enviar el segundo cuestionario. Dado el gran volumen de trabajos

Ciclos de Mejora en el Aula (2020). Experiencias de Innovación Docente de la US C) Esta obra se distribuye con la licencia Creative Commons 
iniciales y finales -casi 300 cuestionarios-, decidí de manera aleatoria tomar una muestra de 35 alumnos para realizar el gráfico -o escalera de niveles-.

El primer cuestionario me ha hecho ver que las preguntas hay que definirlas con enorme detalle, ya que estas han de ser válidas para analizar los avances de los alumnos. A la vista de los resultados, hoy cambiaría algunas cuestiones: de hecho, algunas solo se podrían analizar en un contexto más amplio que el analizado. Es decir, preguntas cuyo avance depende de un contenido posterior, por tanto, imposible de llegar a un nivel de aprendizaje excelente, dado que hay materia que aún no han visto. En todo caso, el cuestionario quedó de la siguiente manera:

PREGUNTA 1.- En la actualidad se está ventilando un proceso judicial de filiación en juzgados de Madrid, en referencia a la filiación de 4 menores de edad. Es el caso de Miguel Bosé y Nacho Palau. Como pareja homosexual durante 26 años, ambos tienen 4 hijos: 2 son biológicos de Nacho y 2 son biológicos de Miguel. (Todos nacieron por maternidad subrogada). ¿Considera usted que son familia? Justifique su respuesta, en cualquier caso.

PREGUNTA 2.- Indique qué ventajas y desventajas observa usted en el matrimonio, respecto a las parejas de hecho, teniendo en cuanta que el matrimonio está regulado jurídicamente, y las parejas de hecho (no de derecho), no lo están.

PREGUNTA 3.- ¿Cree que las disposiciones legislativas autonómicas sobre uniones de hecho deberían ser nacionales? Indique por qué lo cree así: justifique su respuesta.

PREGUNTA 4.- Si usted tuviera potestad para legislar, indiqueme cómo mejoraría las normas juridicas sobre el matrimonio. Tenga en cuenta que las normas suelen ir retrasadas, respecto a los asuntos civiles que regulan.

Ciclos de Mejora en el Aula (2020). Experiencias de Innovación Docente de la US Esta obra se distribuye con la licencia Creative Commons 
PREGUNTA 5.- Si cree que todos los conflictos familiares deben solucionarse por la vía judicial, indiqueme por qué. Y si cree que hay otros medios o alternativas de resolución de conflictos, igualmente dígame cuáles considera que son éstos.

\section{Secuencia de Actividades}

Si se visualizan conjuntamente el modelo metodológico y la secuencia de actividades, puede comprobarse que son paralelos y totalmente extrapolables en cualquier momento. También se observa que, pese a que se indica un tiempo, este ha de ser considerado estimado, ya que por la experiencia que tengo como profesora universitaria, estos tiempos son barajados por el binomio profesor/ alumnos, especialmente cuando estos últimos son muy participativos.

La pretensión no es realizar un seguimiento matemático de este esquema. La flexibilidad es necesaria, no solo en tiempos, sino en el grosso de la clase: explicación, mini casos y contraste. No obstante, esta secuencia de actividades procura una rutina en nuestra aula, que, sin ser inflexible, procura un orden, necesario en este tipo de aprendizaje. Debo marcar unos objetivos reales en la docencia/aprendizaje, y esto no es posible sin la existencia de tiempos y contenidos organizados previamente. Este puede ser un buen esquema para repetir en nuestras clases, a pesar de que se permitan variaciones puntuales, e incluso, pueda modificarse a lo largo del curso.

Quizá lo que más he aprendido como docente al procurar una secuencia de actividades en las clases de Derecho Civil IV - Familia y Sucesiones-, es lo importante que es la definición de la misma: su diseño. Tanto es así, que podría servirles a los alumnos como información sobre las sesiones en esta materia, pudiendo a su vez éstos, dar opiniones sobre la secuencia de actividades e incluso proponer cambios que puedan mejorar la misma.

Ciclos de Mejora en el Aula (2020). Experiencias de Innovación Docente de la US Esta obra se distribuye con la licencia Creative Commons 


\begin{tabular}{|c|c|c|c|}
\hline Secuencia de Actividades & & Patricia Craviotto Valle, & $/ G D U-2$ \\
\hline $\begin{array}{l}\text { ACTIVIDAD } \\
\text { CONTENIDO }\end{array}$ & DESCRIPCIÓN & FINALIDAD & TIEMPO \\
\hline $\begin{array}{l}\text { 1. Saludos / noved ades } \\
\text { Energio positiva y noticios recientes y actuales }\end{array}$ & $\begin{array}{l}\text { Saludar y comen tar noticias } \\
\text { muy actuales so bre Derecho de } \\
\text { Familla. }\end{array}$ & $\begin{array}{l}\text { Centrar la atención del alumno en la } \\
\text { clase y procurar su atención con } \\
\text { noticias novedosas. }\end{array}$ & $3^{\prime}$ \\
\hline $\begin{array}{l}\text { 2. Repaso } \\
\text { Lección de la se sión an terior }\end{array}$ & $\begin{array}{l}\text { Repasar lo comentado en la } \\
\text { dase anterior. }\end{array}$ & \begin{tabular}{|l|} 
Conectar los con tenidos anteriores, con \\
los que se van a ver en esta sesión.
\end{tabular} & $3^{\prime}$ \\
\hline $\begin{array}{l}\text { 3. Planteamien to dudas } \\
\text { Lección de } 10 \text { sesión anterior, o anteriores }\end{array}$ & $\begin{array}{l}\text { Preguntar si existen dudas } \\
\text { respecto a las clases anteriores. }\end{array}$ & $\begin{array}{l}\text { Resolver so bre la marcha, problemas } \\
\text { que tras el estudio de la materia, les } \\
\text { ha yan podido surgir. }\end{array}$ & $\mathbf{2}^{\prime}$ \\
\hline $\begin{array}{l}\text { 4. Resolución dudas } \\
\text { Lección de la sesión anterior, o anteriores }\end{array}$ & $\begin{array}{l}\text { centestar yresolver las dudas } \\
\text { que hayan surgido tras el } \\
\text { estudio, de sesiones anteriores. }\end{array}$ & $\begin{array}{l}\text { Continuar el aprendizaje, sin dudas que } \\
\text { retrasen o entorpezca n la comprensión } \\
\text { de los nuevos contenidos. }\end{array}$ & $2^{\prime}$ \\
\hline 5. Explicación teórica & & & $40^{\prime}$ \\
\hline $\begin{array}{l}\text { 5.1. explicación } \\
\text { Nuevo lección correspondiente a la sesión }\end{array}$ & $\begin{array}{l}\text { Explicar los contenidos que } \\
\text { correspond an ese día. }\end{array}$ & $\begin{array}{l}\text { Avanzar en la materia que nos ocupa, } \\
\text { introduciendo nu evos con tenidos y }\end{array}$ & {$\left[10^{\prime}\right\}$} \\
\hline 5.2. planteamiento y re solución dudas & $\begin{array}{l}\text { Interpelar al alumno, } \\
\text { preguntánd ole si lo } \\
\text { comprenden o tienen dudas. }\end{array}$ & $\begin{array}{l}\text { Que se avance a buen ritmo, salvan do } \\
\text { las dudas que puedan surgir, a nim ando } \\
\text { a que ellos mismos las resuelvan. }\end{array}$ & $\left(5^{\prime}\right)$ \\
\hline $\begin{array}{l}\text { 5.3. explicación } \\
\text { continúa la lección corres pondiente a la } \\
\text { sesión }\end{array}$ & $\begin{array}{l}\text { Continuar explica ndo los } \\
\text { contenidos, aumentando la } \\
\text { profundidad de la materia } \\
\text { o bjeto de estudio. }\end{array}$ & $\begin{array}{l}\text { Seguir avanza ndo en la materia que nos } \\
\text { ocupa, intro ducien do nuevos } \\
\text { contenid os y relacio nán do los con los } \\
\text { anteriores. }\end{array}$ & (10'] \\
\hline $\begin{array}{l}\text { 5.4. plant eamiento y re solución minica } 505 \\
\text { sobre las nuevos explicaciones, pero } \\
\text { incluyendo contenidos previos }\end{array}$ & $\begin{array}{l}\text { Intercalar eje mpl os o minicasos } \\
\text { prá cticos -reales-, y res olverlos } \\
\text { so bre la ma rch a en tre to dos. }\end{array}$ & $\begin{array}{l}\text { Mantener la aten cóón del alumno, } \\
\text { crearle interés a través de casos } \\
\text { verídicos, hacerl es pensar y participar } \\
\text { dando opiniones, yresolver. }\end{array}$ & $\left(5^{\prime}\right)$ \\
\hline $\begin{array}{l}\text { 5.5. explicación } \\
\text { Continua la lección corres pondiente a la } \\
\text { sesión }\end{array}$ & $\begin{array}{l}\text { Terminar de explicar la sesión } \\
\text { teórica y práctica, conforme a la } \\
\text { calend arización del programa } \\
\text { de la asigna tura. }\end{array}$ & $\begin{array}{l}\text { Finalizar los conten idos de la sesión } \\
\text { actual, con el menor número posible de } \\
\text { dudas al respecto. }\end{array}$ & $\left(10^{\prime}\right)$ \\
\hline $\begin{array}{l}\text { 5. Conclu siones y resumen } \\
\text { sobre tada la materia expuesta, onalizaday } \\
\text { comentado en la sesión }\end{array}$ & $\begin{array}{l}\text { Sintetizar todo lo expuesto, } \\
\text { comentad o y an alizado, } \\
\text { resumiendo en un par de frases } \\
\text { el contenido de la sesión. }\end{array}$ & $\begin{array}{l}\text { Crearles un esquema mental muy breve } \\
\text { de todo lo visto en la sesión, de manera } \\
\text { que puedan esquematizar en casa } \\
\text { facilmente, a la hora del estudio. }\end{array}$ & $4^{\prime}$ \\
\hline $\begin{array}{l}\text { 7. Plant eamiento dudas } \\
\text { contenidos de la sesión, conectados con } \\
\text { cualesquiero otros (materia contínua) }\end{array}$ & $\begin{array}{l}\text { Preguntar al alumna do si ha } \\
\text { quedado alguna duda tras la } \\
\text { sintesis final. }\end{array}$ & $\begin{array}{l}\text { Dar la última oportunidad de } \\
\text { participación y resolución de dudas, en } \\
\text { la sesión, antes de su cierre. }\end{array}$ & $2^{\prime}$ \\
\hline $\begin{array}{l}\text { 8. Resolución dudas } \\
\text { cualesquiero contenidos, con prioridad a los } \\
\text { expuestos en lo sesión }\end{array}$ & $\begin{array}{l}\text { Resolver -a ser pos ible-entre } \\
\text { tod os, las últimas dudas, si es } \\
\text { que las hubiera. }\end{array}$ & $\begin{array}{l}\text { Promover la participación del alumnado } \\
\text { en resolver al resto de compañeros, las } \\
\text { dudas que se pudieran plantear. }\end{array}$ & $2^{\prime}$ \\
\hline $\begin{array}{l}\text { 9. Avance próxim os contenidos } \\
\text { Próxima lección, en próxima sesión }\end{array}$ & $\begin{array}{l}\text { Avanzar brevemente los } \\
\text { contenidos que se van a ver en } \\
\text { la próxima clase o sesión. }\end{array}$ & \begin{tabular}{|l|} 
Hacerles ver que todo lo que \\
trabajamos en el aula, es tá conectado y \\
que es necesaria la continuidad en el \\
estudio diario.
\end{tabular} & $1^{\prime}$ \\
\hline $\begin{array}{l}\text { 10. Despedida } \\
\text { 8uenos cons ejos y positivis } m c\end{array}$ & $\begin{array}{l}\text { Despedirnos, des eánd oles buen } \\
\text { dia y esperando verles pronto. } \\
\text { Animarles en el estudio. }\end{array}$ & $\begin{array}{l}\text { Que se despidan igualmente, sintiendo } \\
\text { que en la próxima sesión vamos a ver } \\
\text { cosas muy interesantes e importantes. }\end{array}$ & $1^{\prime}$ \\
\hline
\end{tabular}

Tabla 1. Secuencia de actividades

\section{Resultados de los cuestionarios inicial y final}

A continuación, se expone el resultado de manera gráfica en los diagramas de barras que resultan de la comparación de ambos cuestionarios, teniendo en cuenta que son las respuestas al cuestionario inicial, y las $\square$ son las respuestas al cuestionario final.

Ciclos de Mejora en el Aula (2020). Experiencias de Innovación Docente de la US Esta obra se distribuye con la licencia Creative Commons Reconocimiento-NoComercial-SinObraDerivada Internacional (CC BY-NC-ND 4.0.) 
PREGUNTA 1.- En la actualidad se está ventilando un proceso judicial de filiación en juzgados de Madrid, en referencia a la filiación de 4 menores de edad. Es el caso de Miguel Bosé y Nacho Palau. Como pareja homosexual durante 26 años, ambos tienen 4 hijos: 2 son biológicos de Nacho y 2 son biológicos de Miguel. (Todos nacieron por maternidad subrogada). ¿Considera usted que son familia? justifique su respuesta, en cualquier caso.

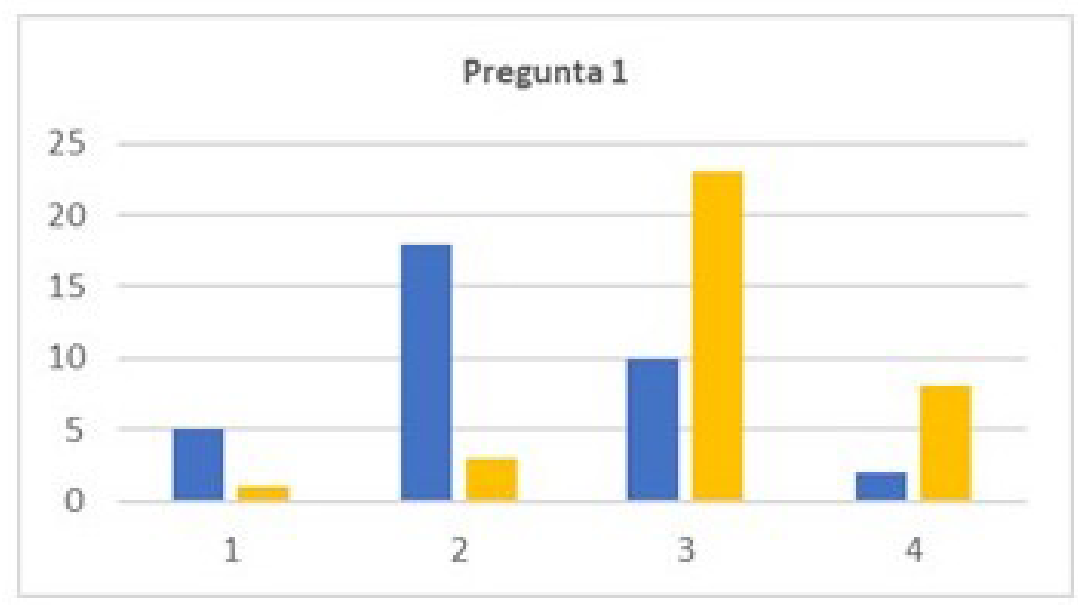

Gráfico 1. Diagrama de barras de respuestas a pregunta 1.

RESPUESTAS a la Pregunta 1:

(1) No son familia.

(2) Son familia de hecho, pero no de derecho.

(3) Si, son familia por opción/decisión.

(4) Son familia, y deben ser reconocidas jurídicamente.

PREGUNTA 2.- Indique qué ventajas y desventajas observa usted en el matrimonio, respecto a las parejas de hecho, teniendo en cuanta que el matrimonio está regulado jurídicamente, y las parejas de hecho (no de derecho), no lo están.

Ciclos de Mejora en el Aula (2020). Experiencias de Innovación Docente de la US Esta obra se distribuye con la licencia Creative Commons 


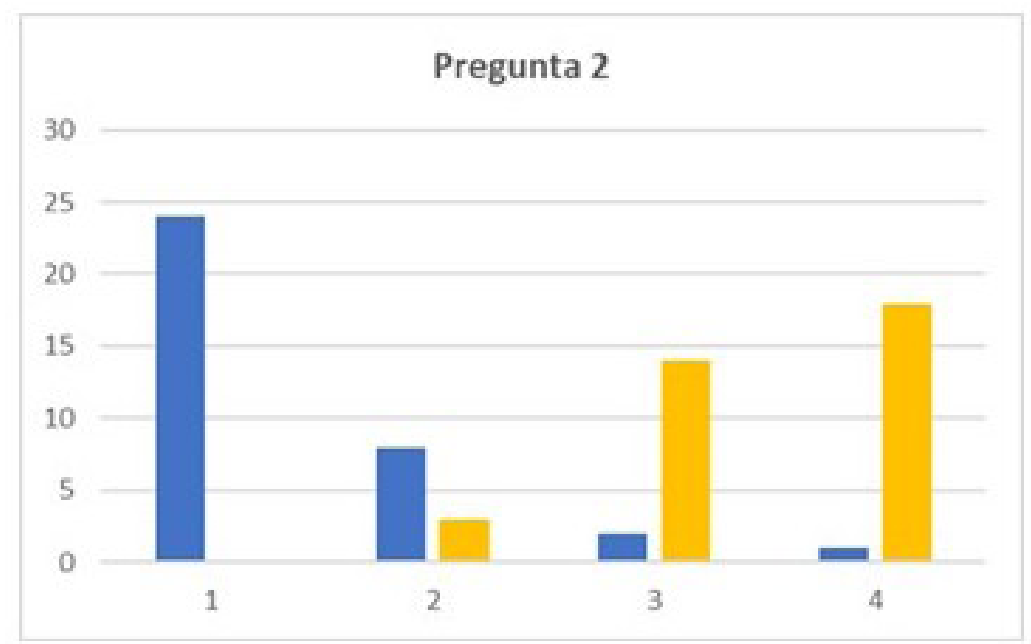

Gráfico 2. Diagrama de barras de respuestas a pregunta 2.

RESPUESTAS a la Pregunta 2:

(1) Ninguna diferencia.

(2) Pocas, pues no se amparan jurídicamente.

(3) Ventajas frente a la Hacienda Pública: IRPF.

(4) Ventajas sociales, económicas y jurídicas.

PREGUNTA 3.- ¿Cree que las disposiciones legislativas autonómicas sobre uniones de hecho deberian ser nacionales? Indique por qué lo cree así: justifique su respuesta.

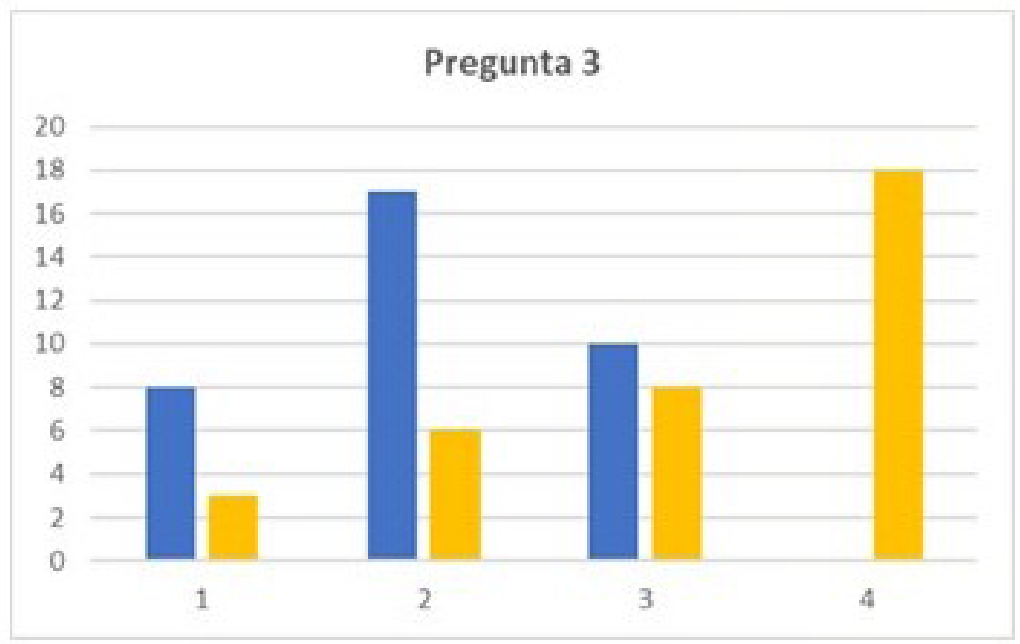

Gráfico 3. Diagrama de barras de respuestas a pregunta 3.

Ciclos de Mejora en el Aula (2020). Experiencias de Innovación Docente de la US (c) E) Esta obra se distribuye con la licencia Creative Commons Reconocimiento-NoComercial-SinObraDerivada Internacional (CC BY-NC-ND 4.0.) 
RESPUESTAS a la Pregunta 3:

(1) No, porque cada pareja se debe a una Comunidad Autónoma.

(2) No, pero quizás debería analizarse y replantearse esta cuestión, jurídicamente.

(3) Si, dado que hay mucha movilidad dentro del territorio nacional.

(4) Si. En caso contrario, el trato es discriminatorio por razón de localización geográfica.

PREGUNTA 4.- Si usted tuviera potestad para legislar, indíqueme cómo mejoraría las normas jurídicas sobre el matrimonio. Tenga en cuenta que las normas suelen ir retrasadas, respecto a los asuntos civiles que regulan.

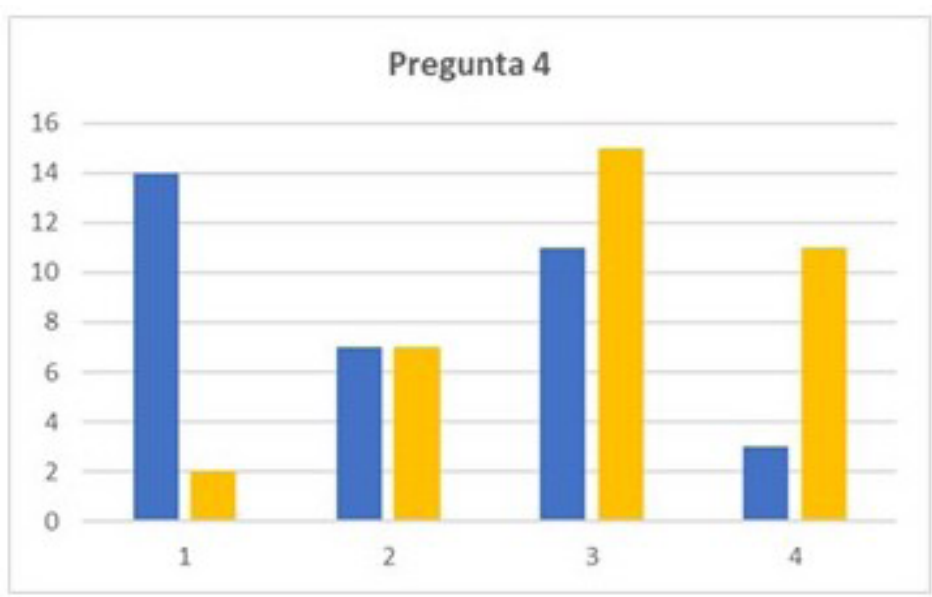

Gráfico 4. Diagrama de barras de respuestas a pregunta 4.

RESPUESTAS a la Pregunta 4:

(1) Están bien. ¿Para qué cambiarlas?

(2) No las cambiaría, pero crearía normas similares para las parejas de hecho inscritas.

(3) El peso histórico del matrimonio grande. Pero hoy, debemos regular otras relaciones.

(4) Adecuaría o asimilaría el matrimonio a otras formas de relación de pareja y familia.

Ciclos de Mejora en el Aula (2020). Experiencias de Innovación Docente de la US Esta obra se distribuye con la licencia Creative Commons 
PREGUNTA 5.- Si cree que todos los conflictos familiares deben solucionarse por la vía judicial, indiqueme por qué. $Y$ si cree que hay otros medios o alternativas de resolución de conflictos, igualmente digame cuáles considera que son éstos.

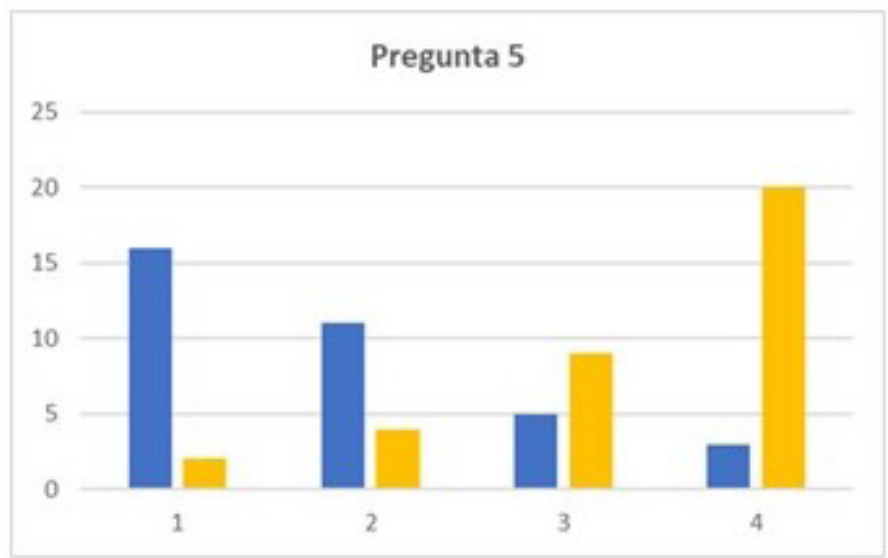

Gráfico 5. Diagrama de barras de respuestas a pregunta 5.

RESPUESTAS a la Pregunta 5:

(1) Son conflictos con efectos muy fuertes. Solo la vía judicial puede solucionarlos.

(2) La vía judicial es más segura para resolver, aunque una opción es la Mediación.

(3) Lo ideal es solucionarse extrajudicialmente, pero es imposible siempre.

(4) Los conflictos familiares pueden resolverse por la Mediación: extrajudicialmente.

\section{Conclusiones}

En la actualidad tengo una perspectiva distinta a la que tenía hace unos meses en referencia a la enseñanza universitaria. Los principios didácticos que he ido trabajando, pienso que mejorarán sustancialmente mi docencia. El carácter científico que puede aportar el alumno en la asignatura de Derecho de Familia y Sucesiones, partirá

Ciclos de Mejora en el Aula (2020). Experiencias de Innovación Docente de la US Esta obra se distribuye con la licencia Creative Commons 
del ánimo que el buen profesor infunda a sus alumnos, para que investiguen su entorno familiar y cercano, lo observen, y en base a las experiencias recibidas, estas se compartan para aportar beneficios al resto de compañeros y al propio docente.

La enseñanza ha de ser asequible para todos, y por ello procuro que el crecimiento personal de cada alumno no dependa de grandes economías o grandes equipos y dispositivos de conexión -por ejemplo-. Tienen muchas herramientas que desconocen o no utilizan y son fuente de conocimiento. Es el caso de las bibliotecas, archivos, compañeros, profesor/a, etc. Herramientas también de autoevaluación personal, que podrían desarrollar a través de las técnicas de estudio -por la parte que les corresponde a ellos-, y de cuestionarios para comprobar el crecimiento del aprendizaje -por parte del profesor/a-.

Relacionar la teoría que leen y/o estudian en los manuales, con la práctica que se analiza en clase -a través de los mini casos-, es una forma de aprender que rompe con la monotonía, especialmente si son casos reales y muy actuales, como el que les propuse en la primera pregunta del cuestionario.

Si los modelos metodológicos, los mapas de contenidos, o la realización de diarios de clase, son importantes, no lo son menos el ánimo y la participación que el alumno ha de desarrollar en las sesiones de clase, al igual que el mantenimiento de la atención. Esta labor también es responsabilidad del docente. El arte o las técnicas que procuren una mejora en la atención del alumno y un buen ánimo en el aprendizaje, habrá de ser un principio didáctico a tener en cuenta siempre. Por ello los dones hay que potenciarlos, y las habilidades hay que practicarlas.

Leer a Don Finkel y observar cómo fue su experiencia al dar clases con la boca cerrada, ha dejado una profunda e impactante huella en la visión que tenía respecto al profesor en el aula. Es cierto que, en la rama del Derecho, no es posible aplicar un sistema exacto al que el autor propone,

Ciclos de Mejora en el Aula (2020). Experiencias de Innovación Docente de la US Esta obra se distribuye con la licencia Creative Commons 
pero demuestra que el alumno siempre tiene algo que decir, y que no siempre el docente está atento a esa necesaria participación del mismo. Para obtener el mejor aprendizaje en Derecho de Familia y Sucesiones, los alumnos han de participar, opinar, realizar críticas constructivas y, sobre todo, compartir dudas y experiencias. Un método de aprendizaje que pueden mejorar mis clases, con las limitaciones que lógicamente deba matizar como docente.

No menos impacto me produjo la lectura de Ken Bain, respecto a qué es lo que hacen los mejores profesores universitarios: el alumno debe descubrir lo que debe aprender partiendo de preguntas y de la interdisciplinariedad, cómo conseguir la atención del alumno y no perderla durante la sesión o clase, promover el interés por aprender con casos reales que puedan resolver, animarlos a que aprendan fuera de las aulas, a que razonen, etc. Herramientas en modo de experiencia, que no de consejos. Todos ellos aplicables a la docencia en Derecho de Familia y Sucesiones, dado que esta materia no solo es jurídica, sino que se transforma en social, desde el momento en el que lo que aprendemos en las clases, está ligado íntima y materialmente con lo que ocurre en la sociedad española: problemas y conflictos familiares de diversa magnitud, que habrán de resolverse -llegados a la vía jurídica- de la mejor manera.

La lectura del libro de Rafael Porlán, ha sido excelente para familiarizarme con conceptos que tienen sentidos distintos desde su lectura, como la evaluación del alumno. Este curso -y en particular esta lectura-, me ha mostrado varias herramientas muy potentes que me permiten obtener información muy valiosa sobre el aprendizaje de mis alumnos, pudiendo así tomar mejores decisiones en la docencia diaria, no solo respecto a cómo poder evaluar a los mismos, sino cómo redirigir mi enseñanza en función de mis alumnos, de los contenidos y del momento en el que vivimos.

Ciclos de Mejora en el Aula (2020). Experiencias de Innovación Docente de la US Esta obra se distribuye con la licencia Creative Commons 
El ejercicio del profesorado universitario no es fácil en ninguna línea de conocimiento, pero en Derecho existe un plus de rigidez autoimpuesto por la propia idiosincrasia de sus procedimientos jurídicos. La transmisión de conocimiento debe partir de la reflexión personal del docente, en referencia a qué transmitir y cómo. Los hoy alumnos, derogarán, modificarán y crearán normas jurídicas; ellos deberán encauzar resoluciones, acordes con los tiempos y su sociedad; deberán esforzarse y trabajar con ilusión. En definitiva, habrán de materializar la mejora de nuestra sociedad. Para eso estudiamos Derecho. Y los docentes, igualmente mejorar.

Palabras claves: Mejora enseñanza; Enseñanza en Derecho; Docencia universitaria, Experimentación docente universitaria.

Keywords: Teaching Improvement; Law Teaching; University Teaching; University Teaching Experimentation.

\section{Referencias bibliográficas}

Bain, K. (2004). Lo que hacen los mejores profesores universitarios. Valencia: Publicaciones Universidad de Valencia.

Finkel, D. (2008). Dar clase con la boca cerrada. Valencia: Publicaciones Universidad de Valencia.

Porlán, R. (Coord.) (2017). Enseñanza Universitaria. Cómo mejorarla. Madrid: Editorial Morata.

Ciclos de Mejora en el Aula (2020). Experiencias de Innovación Docente de la US Esta obra se distribuye con la licencia Creative Commons 